\title{
Una introducción a la imagen literaria del pintor en la España del Siglo de Oro
}

\author{
Javier Portús Pérez *
}

\begin{abstract}
RESUMEN
La literatura española es

extraordinariamente rica en referencias a artistas. En este artículo se estudia la imagen que se deriva de esas alusiones

y se reflexiona sobre los intereses sociales e intelectuales que se hallan detrás de esa imagen. También se trata sobre el carácter instrumental que a veces tenian las menciones a pintores para predisponer a la opinión pública hacia este grupo profesional.
\end{abstract}

ABSTRACT

Spanish literature includes an extraordinary number of mentions to artists. This article studies the idea of the artist that emerges from these literary references, and the social and intellectual concerns that lie behind them. It also deals with the way in which mentions to painters could be used in orden to gain public support for that profession.

La literatura española de la Edad Moderna es, entre las europeas, una de las más ricas en referencias artísticas, que proporcionan al historiador un caudal inestimable de información sobre las expectativas, los usos y los comportamientos de la sociedad ante la obra de arte '. A través de obras de teatro, novelas, relatos hagiográficos, etc., es posible acercarnos a as-

* Conservador. Museo del Prado.

Entre los repertorios generales que recogen parte de esta riqueza informativa figuran Francisco Javier SánCHEZ CANTÓN, Fuentes literarias para la historia del arte español, t. V. Madrid, CSIC, 1941; Miguel Herrero Garcia, Contribución de la literatura a la historia del arte, Madrid, Anexos de la Revista de Filologia Hispánica, 1943; Isabel SANCHEz Quevedo y Miguel Moran TuRina, Pintura y sociedad en la España de Velázquez, Madrid, Akal, 1999. Además de éstas son también muy útiles los estudios y recopilaciones que tratan sobre la información artística que proporcionan autores individuales (Lope de Vega, Calderón, Paravicino, Tirso de Molina, etc., etc.) o géneros literarios (p.e. sermones). 
pectos de la relación entre la sociedad y la pintura para cuya comprensión el estudio de las propias obras de arte, de la documentación de archivo o de los tratados técnicos es a veces insuficiente. La creación literaria es útil en este sentido no sólo por la información explícita que aporta, sino también porque las referencias al arte generalmente se encuentran insertas en un contexto más amplio cuyo estudio permite extender nuestras perspectivas. Así, por ejemplo, un método bastante eficaz para conocer el comportamiento general del público ante las pinturas es el análisis de las escenas teatrales en las que aparece un personaje enseñando un cuadro a otro, que nos permiten advertir hasta qué punto en la contemplación de este tipo de piezas hace trescientos cincuenta años intervenían juicios de carácter narrativo. Incluso esa riqueza en referencias a asuntos artísticos es en sí misma testimonio del interés que entre ciertos sectores sociales despertó todo lo relacionado con el arte ${ }^{2}$.

Muchas veces los protagonistas de esas citas no son el arte o los objetos artísticos en general, sino sus creadores, los pintores, escultores, etc., que aparecen con tanta frecuencia como para que sea posible trazar una imagen literaria del artista. Ésta se compone de mil perfiles, que no son sino reflejo del estatus ambiguo que tuvo la actividad artística en la España del Siglo de Oro, una época que contempló un continuo esfuerzo de los pintores por ver reconocida una categoría social y una importancia intelectual que frecuentemente les negaba parte de la sociedad. En sus reivindicaciones fueron muchas veces ayudados por algunos escritores, quienes se vieron movidos a esta defensa no tarito por un aprecio espontáneo hacia el arte como porque con frecuencia estaban unidos por relaciones de amistad o familia con los artistas. Un ejemplo paradigmático fue Lope de Vega, que procedia de un medio social integrado por artistas y que a lo largo de su carrera aglutinó a un grupo de influyentes pintores y escritores que trabajaban en la Corte y cuya actividad fue fundamental en la campaña de apoyo a la nobleza de la pintura que vivió Madrid durante el primer tercio del siglo XVII ${ }^{3}$.

El primer aspecto que hay que valorar a la hora de estudiar la imagen literaria de los pintores es, pues, el de la existencia de relaciones personales entre literatos $y$ artistas, que fueron a veces estrechas, debido tanto a vínculos familiares como a que los buenos pintores y los literatos

Emilio Orozco (Temas del Barroco de poesia y pintura, Universidad de Granada, 1947) va más allá, y lo explica como consecuencia de la tendencia general a lo pictórico en la literatura barroca española.

He tratado del tema en Lope de Vega y las artes plásticas, Madrid, Universidad Complutense, 1992; y en "Pittura e pensiero nella corte di Spagna agli inizi del XVII secolo", en Luci del Secolo d'Oro spagnolo, Bolonia, Pinacoteca Nazionale, 1998, págs. 71-87. 
frecuentemente se movían en círculos sociales parecidos que posibilitaban su contacto. Además, los escritores estaban al tanto de las líneas generales de la teoría humanista de la pintura, que concebía este arte como una actividad intelectual que comparte con la literatura una naturaleza narrativa y unos fines ejemplares. Las obras de creación literaria del Siglo de Oro están repletas de alusiones al tópico horaciano «Ut pictura poesis", que hermanaba ambas actividades; y aunque a veces se traía a colación para contradecirlo ligeramente y afirmar la supremacía de una sobre otra, lo cierto es que ya estaba instalada en la mente de cualquier persona culta la conciencia del valor intelectual de la pintura. Además, los artistas con más aspiraciones se esforzaron por demostrar cultura, lo que hicieron tanto mediante su integración en círculos intelectuales amplios como a través de la escritura o la especulación teórica sobre su arte, etc. Ese esfuerzo podía responder a un impulso espontáneo o al convencimiento de que en una sociedad como la española, gran parte de cuyos miembros eran analfabetos, la posesión de cultura era también un medio de distinción social. A esto hay que añadir el hecho de que desde finales del siglo XVI se advierte, a través del estudio del coleccionismo, un sensible incremento del interés por la pintura entre las capas medias y altas de la sociedad. Todo ello no podía traer otra consecuencia más que una imagen literaria del pintor construida en términos positivos, acordes con los intereses de los artistas más importantes, aunque no falten visiones más críticas que colocan al arte y sus creadores en una posición social e intelectual ambigua.

Al tratar de estos aspectos no debemos de perder de vista un dato importante. Es cierto que la propia conversión de la pintura y los pintores en tema de todo tipo de creación literaria es prueba de una cierta estima social e intelectual; pero en una sociedad estamental como la española, basada en la codificación de un sistema rígido de privilegios, el factor básico para la distinción social era la estirpe y no la actividad profesional. Por eso, cuando se habla de la nobleza de la pintura y de los pintores hay que relativizarla mucho y no perder de vista que sólo en contadísimas ocasiones estos creadores pudieron auparse más allá de un medio social calificable, con todos las reservas, de "mediana burgesía". Y cuando lo hicieron, fue por razones de sangre y no de oficio. $Y$ en lo que se refiere a esa especie de "hermanamiento" con los escritores que a veces se da, sólo ocurre respecto a los pintores más dotados. De hecho, resulta muy revelador echar un vistazo a los varios "parnasos" o relaciones de hombres ilustres que se hicieron en la época y comprobar que frente a las docenas de escritores que se citan, sólo se suelen mencionar unos cuantos pintores. 
Para tratar de definir las características generales de esa imagen del pintor conviene clasificar las menciones a estos artistas en varios grupos con características específicas, que entre todos cubren casi toda la casuística al respecto. Por una parte, estudiaré las referencias a los pintores antiguos, como Apeles, Zeuxis y Timantes, que aparecen en todo tipo de expresión literaria y de situación argumental; también me interesaré por la conversión de los artistas en personajes teatrales, tanto más interesante cuanto que el teatro fue el espectáculo literario masivo por excelencia y un medio privilegiado para transmitir información a la sociedad e intervenir en su contextura ideológica; otro campo de estudio es el de los cuentecillos paródicos, que con mucha frecuencia protagonizan artistas, y en los que se transmite una imagen sobre ellos a veces paradójica y siempre muy dependiente de las leyes de este particular género literario. Por último, abandonaré a los pintores míticos o ficticios y aludiré rápidamente a un tipo de producción literaria que en sí misma es reveladora de la importancia social e intelectual de algunos artistas: me refiero a los poemas dedicados expresamente a alabar a pintores contemporáneos o algunas de sus obras.

Aunque en estas páginas vamos a atender fundamentalmente a lo que podríamos calificar como "creación literaria", sería falaz pensar que existen diferencias sustanciales entre la imagen literaria del pintor y la que deriva de fuentes supuestamente más objetivas, como los tratados o los repertorios biográficos. Durante la Edad Moderna existía un concepto del género biográfico distinto al de hoy en día, y en las construcciones de las vidas de los artistas se admitían numerosas licencias, como es la utilización de información no verificable documentalmente para perfilar la imagen de un personaje según los intereses de su biógrafo. En muchos aspectos la narración biográfica era una construcción legendaria, como ocurre con casos muy conocidos como el de Alonso Cano ${ }^{4}$. Tanto el literato como el tratadista disfrutaban de una gran libertad para construir la vida o la imagen de los pintores, y en muchos casos no interesaba tanto la descripción de una peripecia vital individual cuanto las posibilidades que ésta ofrecía para caracterizar colectivamente a un grupo profesional.

Las fuentes literarias permiten reconstruir una imagen profesional del pintor y reconocer los tópicos más comúnmente asociados con su actividad.

\footnotetext{
"He tratado del tema en "Alonso Cano: La creación de una leyenda", en AA.VV., Veintitrés biografias de pintores. Museo del Prado, Madrid, Fundación Amigos del Museo del Prado y editorial Mondadori, 1992, págs. 319-344. En este mismo número de “Espacio. Tiempo y Forma" se incluye un artículo de MIGUEL FALOMIR que demuestra hasta qué punto la imagen biográfica que se nos ha transmitido de Juan de Juanes es una construcción legendaria con escasos apoyos históricos.
} 
También hacen posible trazar un perfil psicológico arquetípico de estos creadores, aunque hay que decir que éste, cuando aparece, se basa más en esquemas tópicos que en una reflexión profunda y personal. En esto la literatura española refleja muy bien las bases sobre las que se asentaba la tarea de definición de la personalidad artística que desde el Renacimiento se estaba llevando a cabo en otros países europeos, y que ha dado origen a varios e importantes ensayos. Unas cuantas citas salidas de la pluma de escritores distintos pueden servir para definir los rasgos psicológicos más importantes atribuidos al pintor. $Y$ lo más significativo es que siempre que un literato se refiere a estos profesionales como dueños de una personalidad diferenciable, lo hace en términos parecidos.

En general se les atribuye una personalidad con rasgos muy acusados, y abundan los escritores que gustan incluirlos entre los extravagantes y locos. En una obra temprana como el Viaje de Turquia son calificados como "perdidos", junto con los esgrimidores y los maestros de danzar ${ }^{5}$; Lope de Vega, en El peregrino en su patria los coloca en la categoria de los "locos", al lado de poetas, trazadores y alquimistas 6; Francisco Cascales en sus Cartas filológicas afirmaba que "Diógenes, cuando consideraba en el mundo a los astrólogos, farautes de sueños, adivinos, poetas y pintores, y otros de este género, juzgaba que no había en la tierra cosa más desdichada que el hombre" "; Francisco de Quevedo, en sus Sueños y discursos hace que entre los desquiciados seguidores del alma de Garibay se encuentren, entre otros, los pintores "; y Luis Vélez de Guevara en El diablo cojuelo los hermana en cuanto a extravagancia y locura con los poetas y músicos ${ }^{9}$. La alusión a la locura como característica

"Juan de Voto a Dios: Contábame un dia el duque (de Medinaceli), que es mi hijo de confesión, que habia tenido su padre un pintor, hombre muy perdido.

Matalascaliando: No es cosa nueva ser perdidos los pintores; más nueva sería ser ganados ellos, y los esgrimidores y maestros de danzar y de enseñar a leer a niños ¿Habéis visto algunos destos ganado en cuanto habéis peregrinado?" Viaje de Turquía, ed. F. Garcia SaLINERO, Madrid, Cátedra, 1980, págs. 353-354.

"No le dejaron pasar adelante los donaires y confusas voces de los atros locos ni ya desde aquel punto fue posible sosegarse, aunque quedaba gran cantidad de pintores, trazadores, poetas y otros artífices, entre los cuales lucian dos, un alquimista y un famoso discípulo de Raimundo Lulio". LOPE DE VEGA, El peregrino en su patria, ed. J.B. Avalle-ARCE, Madrid, Castalia, 1973, pág. 345 .

F. Cascales, Cartas filológicas, ed. J. Garcia Serrano, Madrid, CSIC, 1961, I, pág. 46.

Sueños y discursos, ed. F. Maldonado, Madrid, Castalia, 1980, pág. 234.

"Celebradisimo fue el papel del Engañado por peregrino y caprichoso (...) que decía desta manera: «Pronóstico y lunario del año que viene al meridiano de Sevilla y Madrid, contra los poetas, músicos y pintores". Se trata de una academia poética.

Luis Vélez de Guevara, El diablo cojuelo, tranco X, Biblioteca de Autores Españoles, t. 33 pág. 44. 
psicológica del pintor es un tópico en la literatura europea de la Edad Moderna, y en el fondo se trata de una caracterización ennoblecedora, por cuanto es una referencia al fuerte componente mental o intelectual que requiere el ejercicio de ese arte. De hecho, los escritores se complacían en colocarse tópicamente a sí mismos también en el grupo de los locos, como demuestran algunas de las referencias anteriores o una epístola en verso por la que Gutierre de Cetina pide a Diego Hurtado de Mendoza una pintura de Tiziano:

"En este punto que postrero toco / de pediros, vereis que soy poeta, / si no lo habiades visto en que soy loco" "'.

La locura, y especialmente aquella que se consideraba producto de una actividad intelectual, se relacionaba frecuentemente con el humor melancólico, al que se creía producto de una excesiva activación de la imaginación. El pintor y tratadista Francisco Pacheco describe la alegoría del arte de la Pintura como una mujer con los cabellos negros, crespos, sueltos y continuamente revueltos, a causa de su continua ejercicio de la mente y de la imaginación, lo que le produce melancolia " ${ }^{11}$. Esa caracterización está basada en una larga tradición que se expresa a través fundamentalmente de tratados de arte. Pero en algunos escritores españoles ajenos al mundo y los intereses de la tratadística también se encuentra una relación similar entre actividad artistica y temperamento melancólico, como en Tirso de Molina, que convirtió a un pintor en uno de los personajes de su novela Los tres maridos burlados. De él dice que necesitaba del auxilio del ocio y de las fiestas «para divertir melancolias que la asistencia contemplativa deste exercicio comunica a sus profesores" ${ }^{12}$.

Los compiladores de las biografías de artistas gustaban insistir en los rasgos de soberbia de sus héroes, que servian para llamar la atención sobre la fuerte personalidad de algunos de estos personajes que en ocasiones se atrevían a tratar en un plano de igualdad a los poderosos. En alguna ocasión, esa cualidad sirvió para caracterizar globalmente a los pintores, como hizo el famoso poeta y predicador fray Hortensio Félix Paravicino en un sermón dedicado a San Lucas, en el que afirmaba que el evangelista "supo ser gran pintor sin ser soberbio, divino achaque desta espiritual arte, desta lisonja animada de la naturaleza, que comenzando

10 Cito por Sanchez Canton, Fuentes ...; op. cit., t. V, págs. 334-335.

Francisco Pacheco, Arte de la pintura, ed. F.J. Sánchez Cantón, Madrid, 1956, t. I, pág. 99. TiRso de Molina, Los tres maridos burlados, Barcelona, G. Margarit, 1631, pág. 175. 
dotrina o copia se pasa más veces a emulación, tal a ventaja» ${ }^{13}$. El mismo autor, que fue un gran aficionado a la pintura y reconoce que tenía frecuente trato con pintores, halla el origen de esa soberbia en la constatación por parte del artista de sus propios poderes creativos ${ }^{14}$.

El resto de alusiones a una caracterización psicológica de los pintores que he encontrado se mueven en torno a parámetros parecidos. Lope de Vega, en su comedia Mirad a quien alabáis afirma que el pintor es en general amigo de alabanzas, sobre todo entre los de su profesión, al igual que el poeta y el músico, con lo que encontramos un ejemplo más de ese hermanamiento en cuanto al carácter entre artistas y literatos ${ }^{15}$. El mismo escritor en Del monte sale hace decir a un personaje que "el poeta y el pintor / confesarán que no saben" antes que él mismo se obligue al amor ${ }^{16}$. Por su parte, Juan Francisco Andrés de Ustárroz, en su Universidad de Amor (1649) se hace eco del tópico sobre el secretismo de algunos artistas hacia su trabajo cuando describe una sala en la que había algunos personajes que "guardaban los dibujos como oro en paño, que siempre las profesoras de esta nobilísima arte son escasas en mostrar sus trabajos" "

El pintor, como el poeta, aparece caracterizado como un ser cuya actividad creativa refleja o produce una personalidad especial, cuyos rasgos están relacionados con el ejercicio continuo de la mente. En la insistencia que hacen los tratadistas desde el Renacimiento en la definición de la pintura como actividad mental, frecuentemente van más allá y sugieren que es también una labor "temperamental", en el sentido de que el estilo de un pintor depende en parte de su propia contextura emocional. Con eso dan una paso más en la definición de este arte, y a su caracterización científica y codificable añaden un componente eminentemente personal, con lo que insisten en su dimensión irrenunciablemente individual. En

Fray hortensio Félix Paravicino, Oraciones evangélicas, Madrid, 1640, pág. 183 (Cito por J.M. CAAmaño, "Paravicino", Revista de ldeas Estéticas, t. XVIII (1970), págs. 152-153). Sobre la actitud de Paravicino ante la pintura he tratado en JAVIER PORTus, "Fray Hortensio Paravicino: La Academia de San Lucas, las pinturas lascivas y el arte de mirar». Espacio Tiempo y Forma, Serie VII, t. X (1996), págs. 77-105.

«Alaba un pintor famoso, un Urbina, un Parmesán, una tabla de lo primo, de lo valiente -que allá dicen y acá hemos tomado-, y, enamorándose tanto de ella, llévale los ojos de modo su pincel arrebatado y desvanécelo de manera que la hace quitar allá ¿Es posible que yo he hecho esto?". Cito por CaAmaño, «Paravicino», op. cit., págs. 152-153.

5 "Rey: Resuélvome que al letrado, / entre los hornbres de letras, / se ha de alabar con templanza, / pues los demás le respetan /.../ al músico, sin exceso / con los que el arte profesan; / al pintor entre pintores; / al poeta, entre poetas". LOPE DE VEGA, Mirad a quien alabáis, En Obras de Lope de Vega, ed. E. Cotarelo, Madrid, R.A.E., 1916-1930, t. XIII, pág. 34.

16 En Obras de Lope de Vega, ed. E. CotaRelo, Madrid, R.A.E., 1916-1930, t. II, pág. 61

17. Cito por RICARDO DEL ARCO, La erudición aragonesa en torno a Lastanosa, Madrid, 1934, t. I, págs. 89-90. 
España el interés por este tema se encuentra desde los Comentarios de la pintura de Felipe de Guevara y se advierte en todos los tratados, en los que no faltan párrafos que justifican el estilo o los temas que cultiva el pintor en función de su propio temperamento. Del asunto se hicieron eco también los literatos, como Juan Pérez de Montalbán, quien en su Orfeo en lengua castellana escribió: "Suele seguir la inclinación la mano, / diferencia que prueba la pintura, / pues el pintor de condición humano / pone mayor estudio en la hermosura: / el feo, el arrogante, el inhumano, / que tiene condición áspera y dura, / pinta fieros escorzos, y esta parte, / que es propia en él, disculpa con el arte» ${ }^{18}$.

Uno de los conceptos fundamentales para entender el pensamiento occidental desde la Edad Media es la «idea de autoridad»; es decir, la noción de que existen una serie de fuentes ya establecidas de conocimiento que tienen una naturaleza casi infalible. Con el tiempo cambiaron las referencias pero se mantuvo esa fe en los modelos; y la forma en la que desde el Renacimiento se fue contestando a esa fórmula epistemológica y fue ganando terreno la confianza en la experiencia personal como medio para conocer la realidad constituye una de las bases de la historia del pensamiento moderno. El principal punto de referencia cultural de esa época fue la Antigüedad grecorromana, cuya abundante literatura proporcionaba inagotables referencias trasladables a la experiencia cotidiana. En el caso del arte, la Historia natural de Plinio y numerosas obras de creación literaria, filosofía o historia proporcionaban un cuantioso caudal de noticias sobre pintores, escultores y arquitectos antiguos que fueron muy utilizadas por los literatos modernos y que sirvieron para construir una imagen del artista que en el fondo estaba en bastante consonancia con los intereses de los pintores de la época.

A pesar de algunas reticencias de escritores como Séneca, la Antigüedad proyectó una imagen en general ennoblecedora del pintor, entre otras cosas porque las referencias a artistas $u$ obras de arte frecuentemente tenían una función metaliteraria; es decir, se aprovechaba en ellas el carácter narrativo de la pintura, que era una característica que hacía de este arte una actividad intelectual y noble. Eso fue algo que también ocurrió en la literatura española de la Edad Moderna. Casi siempre

${ }_{18}$ Orfeo en lengua castellana, Madrid, 1624, canto III, fol. $21 \mathrm{r}-\mathrm{v}$. 
que se cita en ella a un artista es para alabarle, y cuando se hace alusión a una obra de arte, generalmente se alude a su valor o su belleza o se utiliza por sus posibilidades narrativas o literarias. De hecho, algunos escritores sobre arte, como Bosser, insistieron en que la abundancia de referencias antiguas sobre la materia es prueba de lo mucho que fue estimada esa actividad ${ }^{19}$. Sólo en contextos paródicos es posible encontrar una opinión peyorativa respecto a los pintores, que no procede en ningún caso de una minusvaloración de su actividad sino que se justifica por el mal ejercicio del arte en casos particulares. Pero a la hora de valorar la imagen literaria del pintor hemos de tener en cuenta dos cosas: por una parte, la existencia a veces de cierto desacuerdo entre esa imagen escrita y la realidad social cotidiana, que no siempre era tan favorable hacia los artistas. Por otra parte, hemos de pensar que esa imagen pudo servir para modificar esta realidad social, como sugiere el hecho de que uno de los principales saltos cualitativos que se han dado en el país en el estatus de la profesión del pintor (el que se produjo en el primer tercio del siglo xVII) coincidió con la existencia de campañas literarias en favor de estos profesionales.

A medida que transcurría la Edad Moderna española el caudal de conocimientos sobre artistas españoles y extranjeros fue aumentando, asi como el interés por su personalidad y su obra, lo que hizo que cada vez fuera más habitual encontrar sus nombres en las obras de creación literaria. Además, hubo una serie de pintores modernos que, como veremos más adelante, alcanzaron categoría de tópicos. Sin embargo, los artistas más frecuentemente citados durante todo ese periodo fueron sin excepción Apeles, Timantes, Zeuxis y otros creadores griegos ensalzados por la literatura romana. El número de alusiones es realmente abrumador, y en estas páginas sólo quiero tratar de algunas cuestiones generales relacionadas con el tema ${ }^{20}$.

Las anécdotas clásicas en España fueron seleccionadas, adaptadas e interpretadas atendiendo a los intereses particulares de los escritores. Así, mientras que un literato como Saavedra Fajardo, ajeno a las preocupaciones profesionales de los artistas, alude al ayuno de Protógenes de forma casi paródica, Jáuregui utiliza esa historia para demostrar que no se precisa vigor físico para pintar, y que el arte es una actividad que depende esencialmente del cerebro ${ }^{21}$. Sin embargo, la imagen que generalmente se quiere proyectar a través de este tipo de referencias es positiva y ennoblecedora.

\footnotetext{
Cito por Francisco Calvo Serraller, La teoría de la pintura en el Siglo de Oro, Madrid, Cátedra, 1981, pág. 574.

20 He tratado de forma más extensa sobre el asunto en Lope de Vega ..., op. cit., págs. 359-383.

2) En su Memorial sobre la nobleza de la pintura. Cito por Calvo Serraller, Teoria ..., op. cit., pág. 360 .
} 
A través del anecdotario clásico, los escritores de la Edad Moderna disponían de una amplia casuística sobre la personalidad del artista, la naturaleza y función de las obras de arte y la relación entre pintores y clientes; aspectos todos que se resolvían de una manera cercana a las expectativas de la teoria humanista de la pintura. Los escritores gustaron de comentar y difundir precisamente aquellos relatos más cercanos a los intereses contemporáneos. Uno de los temas fundamentales de los tratados de arte de la época era el de la relación entre el pintor y la naturaleza, que admitía una doble actitud: la que reivindica su copia exacta, y la que aboga por una imitación selectiva que emule el proceso creativo natural o divino; y es sintomático que varias de las anécdotas clásicas más repetidas tengan como tema estos asuntos.

El proceso selectivo que conduce a la plasmación de una belleza ideal aparece perfectamente reflejado en la narración sobre la elaboración de una pintura de Helena por Zeuxis, que realizó convocando a las cinco doncellas más hermosas de Crotona y eligiendo los rasgos más perfectos de cada una de ellas ${ }^{22}$. Según Kris y Kurz, esta historia se encuentra en el origen del concepto de "Alter Deus" ${ }^{23}$, y referencias a ella aparecen en multitud de obras literarias del Siglo de Oro, en las que se utilizan para muy diversos propósitos. Muy frecuentemente se interpreta de forma literal y se usa como elemento de comparación trasladable a la práctica literaria o a situaciones cotidianas. Así, José Pellicer se valió de ella para explicar el nacimiento de Lope de Vega: «Para copiar el retrato de Helena pidió Zeuxis las más hermosas vírgenes de Cloto y de Argento; tomando de cada cual las más perfectas facciones. De este modo la naturaleza entresacó lo más admirable, escogió lo más raro de todos los varones famosos antiguos, para crear a Lope, haciendo en su creación el último esfuerzo, y echando el resto de su poder ${ }^{24}$. Son muy interesantes los casos en los que el escritor asume que la historia es conocida por todos, y la utiliza de forma, digamos, paradójica, como hizo Lope de Vega en un soneto dedicado a Ángela Vernegali, en el que afirma que el pintor hubiera tenido bastante con fijarse exclusivamente en ella ${ }^{25}$.

2. Hablan de ello Plinio (Historia natural, XXXV, 64) o Cicerón (De invent., II, 1). Un rápido repaso a su fortuna en la tratadística europea, en la edición de Francisco Calvo SERRALLER de Vicente Carducho, Diálogos de la pintura, Madrid, Turner, 1979, pág. 166.

23. Ennst Kris y Otto Kurz, La leyenda del artista, Madrid, Cátedra, 1982, pág. 63.

24 Juan PEREz DE Montalbán, Fama pósthuma de Lope de Vega, Madrid, Imprenta Real, 1635. fols. $104 \mathrm{v}-105 \mathrm{r}$.

2s Colección escogida de obras no dramáticas de Lope de Vega, Madrid, Atias, 1950, pág. 383b. Sobre el soneto, véase Aurora EGIDO, «La página y el lienzo: sobre las relaciones entre poesía y pintura", en sus Fronteras de la poesia en el Barroco, Barcelona, Crítica, 1990, pág. 181 
La imitación exacta del mundo visible encontraba su ejemplo paradigmático en las uvas pintadas con tanta perfección por Zeuxis que las aves se acercaban a ellas con intención de picotearlas ${ }^{26}$. La anécdota llamaba tanto la atención por su valor ejemplar en una época cuyo arte tenía aspiraciones ilusionistas, que no sólo aparecia en todo tipo de literatura, sino que se convirtió también en un modelo en el que se basaron leyendas similares atribuidas a pintores modernos. Ustárroz aludió a una tapicería en la que "se ha visto verificada la contienda de Zeuxis, pues en un mismo día llegó un paño real representando unas uvas y lloró un niño porque no se las daban" ${ }^{27}$; Ferrer de Valdecebro se refiere a un águila que se abalanzó sobre un lienzo en el que estaban pintadas unas uvas ${ }^{28}$, y Palomino nos cuenta que las azucenas del San Antonio de Murillo y un estanque de una Susana y los viejos de ${ }^{29}$ Antonio Garcia Reinoso lograron engañar a los pájaros. No faltan tampoco cuadros de la época en los que se representan aves picoteando frutas, en los cuales se puede apreciar una alusión a esa anécdota y al poder ilusionista de la pintura.

Según la literatura antigua, un desconcierto similar al que sufrieron los pájaros padeció el propio Zeuxis cuando intentó descorrer una cortina que creía ocultaba un cuadro y que en realidad habia sido pintada por Parrasio. La historia fue muy querida por los escritores del Siglo de Oro, como Gabriel Lasso de la Vega, que le dedicó un extenso romance, o Manuel Faria, que escribió dos curiosas octavas sobre él ${ }^{30}$. La causa de su popularidad estriba en que al tema del poder ilusionista del arte se une el de la competencia ingeniosa entre los artistas.

Durante la Edad Moderna se reivindicó constantemente el carácter intelectual de la pintura, de manera que se consideró competencia del artista no sólo imitar la realidad sino también crearla, y convertir su oficio en un medio de transmisión de pensamiento. El arte tenía una función eminentemente narrativa, que exigía al pintor, además de cultura, ingenio para resolver los problemas de la representación. Por eso, entre las anécdotas clásicas más apreciadas en el Siglo de Oro figura la que nos cuenta que Timantes ocultó con un velo el rostro de Agamenón para así expresar el

\footnotetext{
26 Plinio el VIEJo, Historia natural, XXXV, 65.

27 F. ANDRES DE USTARROZ, Descripción de la casa de Lastanosa. Cito por ARCo, La erudición aragonesa ..., op. cit., pág. 221.

as Gobierno general, moral y politico hallado en las aves, Madrid, 1670. Cito por HERRERO, Contribución ..., op. cit., pág. 42.

${ }^{29}$ Vidas, ed. N. Ayala, Madrid, Alianza, 1986, págs. 292 y 258.

30 Gabriel LASSO DE LA VEGA, Primera parte del romancero y tragedias, Alcalá, Iuan Gracián, 1587, fols. 32v-34r.; Manuel Faria, Fuente de Aganipe, Madrid, Juan Sánchez, 1644, fol. 108v.
} 
inefable dolor que sintió ante el cadáver de su hija Ifigenia ${ }^{31}$. Frecuentemente se alude al tema de forma directa; pero, al igual que ocurría con la Helena de Zeuxis, también abundan las citas abreviadas que demuestran que la historia era del dominio público. Lope de Vega, en El Isidro trata de describir a María de la Cabeza, y dice : «Pues la novia yo no sé / cómo pintarla podré, / si no es que, como Timantes, / la cubra a los circunstantes, / porque la entiendan por fe " ${ }^{32}$; Miguel de Barrios en una oración fúnebre habla del «velo / que el Timantes mortal le pone al cielo»; y Mateo Alemán, que seguramente escribía de memoria, hace protagonizar una historia similar a un pintor anónimo" ${ }^{33}$.

Bastante difundida, relacionada también con Timantes, y alusiva a la inteligencia con que los artistas en ocasiones solventaban los problemas derivados de la representación es una anécdota que nos habla del ingenio que demostró el pintor al plasmar la grandeza de un gigante mediante un enorme dedo que está siendo contemplado por dos sátiros ${ }^{34}$. Lasso de la Vega consideraba esto una expresión de la "subtil inventiva artificiosa" de su autor, y una prueba de que al arte (en el sentido de actividad intelectual) nada se le resiste ${ }^{35}$; y el dramaturgo Bances Candamo nos cuenta que a través de un solo soneto supo de la pésima calidad de tres comedias "porque conocí por el dedo el gigante" ${ }^{36}$.

La gran cantidad de menciones a estas anécdotas que aparecen en la literatura española de la época y, sobre todo, el hecho de que en la narración de muchas de ellas se da por supuesto su conocimiento por parte del lector, nos prueba lo muy difundida que estaba la imagen del pintor como un creador ingenioso e inteligente cuya misión es imitar la naturaleza, mejorarla en su caso y transmitir un contenido narrativo. Sin embargo, de entre todas esas historias fue la de las uvas de Zeuxis la que alcanzó un mayor éxito, hasta el punto de que sivvió para estructurar otras historias atribuidas a pintores modernos. Esto sugiere que la mentalidad colectiva de la época seguia considerando la pintura un arte esencialmente ilusionista, y apreciaba al pintor en

PLINIO, Historia Natural, XXXV, 73.

37 Obras completas de Lope de Vega, ed. J. de Entrambasaguas, Madrid, CSIC, 1965, t. i, pág. 290b.

${ }_{33}$ Miguel DE BARRios, Sol de la vida, Amberes, Jacob van Velven, 1679, pág. 584; La cita de Mateo Alemán procede de su novelita Ozmín y Daraja, incluida en Guzmán de Alfarache. Véase D. McGrady, "Mateo Alemán y Timantes, o la expresión del indecible dolor de los padres", Revista de Filologia Española, t. LXV (1985), págs. 319-321.

i4 La anécdota deriva de PLINIO, Historia Natural, XXXV, 73.

35 LASSO DE LA VEGA, Primera parte ..., op. cit., fol. 136r-v.

${ }_{36}$ Theatro de los theatros de los pasados y presentes siglos, ed. D.M. Moir, Londres, Támesis, 1970, pág. 50 . 
la medida en que era capaz de hacer confundir lo representado con su representación.

El artista clásico más citado en la literatura española de la Edad Moderna fue Apeles, cuya variada biografía proporcionó una auténtica cantera de anécdotas que cubrian casi toda la casuística de la creación pictórica ${ }^{37}$ y fue convertido en un auténtico arquetipo de pintor. Julio Caro Baroja manifiesta que estamos ante un arquetipo cuando "se piensa en algo que reuniendo las características de varios ejemplares, corresponde a una noción general y superior a ello", y manifiesta la posibilidad de su personificación ${ }^{38}$. La reunión de esas caracteristicas en la persona de Apeles ya fue realizada en la época clásica, cuando se atribuyeron al pintor una serie de anécdotas y realizaciones artísticas con un origen legendario, pero que servían para dar una idea completa de lo que debía ser un pintor áulico ${ }^{39}$. Durante el Siglo de Oro el proceso fue continuado, y la leyenda se enriqueció con la adición de una serie de episodios que proceden de las biografías de otros artistas antiguos y que completaban aspectos que se podían echar de menos en la de Apeles. Un ejemplo muy significativo aparece en El criticón, donde Gracián escribe: "Vieron ya en las oficinas del tiempo y del ejemplo, formarse un grande hombre, copiándolo más felizmente de este héroe que el retrato de Apeles de las siete mayores bellezas" ${ }^{40}$. Casi todos los relatos sobre Apeles que citan las fuentes hacen referencia al poder ilusionista de su pintura, y sólo el de Antígono a su capacidad de corregir y mejorar la naturaleza, de lo que fue un verdadero paradigma esta anécdota de Zuexis. No es de extrañar, pues, que Gracián haya atribuido una de las leyendas pictóricas más importantes de la Antigüedad al pintor más famoso de ella, cuya biografía carece de episodios destacados de significación similar a la de este ${ }^{41}$.

\footnotetext{
3) Portús, Lope de Vega..., op. cit., págs. 366 y ss.; Frederick A. Armas, “Pintura y poesía: la presencia de Apeles en el teatro de Lope de Vega", en M. CRIADO DEL VAL (ed.), Lope de Vega y los origenes del teatro español, Madrid, 1981, págs. 719-732.

so Julio Caro Baroja, De arquetipos y leyendas, Barcelona, Círculo de Lectores, 1989, pág. 24.

39 Legendarias han de cosiderarse muchas de las anécdotas sobre la relación entre Apeles y Alejandro que reflejan una consideración social del pintor que otras fuentes han demostrado discrepante con la realidad. Véase B. BIANCHI BANDINELLI, "L'artista nell'antichitá classica", Archaeologia Classica, t. IX (1957), págs. 4-5. Esto ocurre, por ejemplo, con las burlas que sufrió Alejandro por parte de Apeles, completamente impensables en una relación entre un príncipe antiguo y un pintor, y que han sido estudiadas por S. REINACH en "Apelles et le cheval d'Alexandre", Revue Archeologique, t. V (1917), págs. 189-197. Otras anécdotas legendarias son las basadas en la ilusión extrema de realidad de algunas de las realizaciones artísticas de Apeles, y que se inscriben en un nutrido conjunto de historias similares que hacen hincapié en el poder casi mágico de la práctica artística.

40 Baltasar Gracian, Obras completas, ed. E. Correa, Madrid, Aguilar, 1944, pág. 760.

${ }^{4}$ No fue el aragonés una excepción en la atribución de la Helena a Apeles, pues ya Lope de Vega lo había hecho poco antes en su comedia Las mujeres sin hombres. Véase ARMAS, "Pintura y poesía ...", op. cit., pág. 721.
} 
Igualmente a Apeles se atribuyeron en varias ocasiones algunas de las anécdotas más famosas que se han citado más arriba, como la de las uvas de Zeuxis ${ }^{42} \mathrm{o}$ el dedo de Timantes ${ }^{43}$.

Otra manifestación de su conversión en arquetipo es que se le hiciera protagonista de algunos hechos completamente inventados; un dato que encuentra su verdadero valor cuando se constata que con ningún otro artista ocurrió algo semejante de una manera tan frecuente. Generalmente se trata de pinturas que las fuentes antiguas no recogen, como un Amor pisando libros y espadas ${ }^{44}$ o una Desdicha sin ojos realizada por encargo de Alejandro ${ }^{45}$. A veces son relatos sobre su relación con sus colegas, una de las cuestiones que con mayor frecuencia aparecen en los relatos sobre artistas. Alonso de Bonilla, por ejemplo, para referirse al "perfeccionamiento" que llevó a cabo San Vidal en la anatomía de los tullidos que sanó, que antes eran auténticos "bosquejos" del Creador, alude a un cuadro que habia comenzado Apeles (Dios) para que algunos de sus compañeros trataran de acabarlo, "mas ninguno la vio que se atreviera, / a tan difícil prueba, y tan oscura" ${ }^{46}$. Otras veces se le atribuyen historias que revelan una personalidad completamente distinta a la que aparece en la fuentes, como hizo Juan de Mal Lara cuando lo utilizó para personificar al "hombre vergonzoso" ${ }^{47}$. Para acabar de caracterizar a Apeles como un pintor moderno, se le atribuye con frecuencia una costumbre a la que no hacen referencia las fuentes. Se trata de la de firmar sus cuadros, a lo que aluden Covarrubias o Diego Lozano, quien afirmaba que era inútil su firma, porque la propia obra descubría sin duda a su autor ${ }^{48}$.

La sustitución de la palabra "pintor» por el nombre de Apeles constituye otra prueba de su conversión en modelo. Fue una práctica muy habitual, que en ocasiones adquirió caracteres muy significativos, como cuando Lope de Vega en El niño inocente de La Guardia califica a Dios como "el divino Apeles" ${ }^{49}$.

\footnotetext{
42 Por ejemplo, J. Porras, Rimas varias, Antequera, I.B. Moerira, 1639, fol. 75 r.

${ }_{43}$ P. GRAnde DE TENA, Lágrimas panegiricas a la temprana muerte de... Juan Pérez de Montalbán, Madrid, Imprenta del Reino, 1639, fol. 56r.

${ }^{44}$ ARMAS, “Pintura y poesía ...", op. cit., pág. 721.

45 Comedias escogidas de Lope de Vega, t. II, Madrid, Atlas, 1950, pág. 414c.

46 Peregrinos pensamientos, Baeza, Pedro de la Cuesta, 1614, fol. $199 \mathrm{v}$.

4t Philosophia vulgar, Sevilla, Hernando Diaz, 1568, fol. 253r.

48 Gloriosos triunfos, solmenes fiestas ... en la canonización de ... Santa Maria Magdalena de Pazzi, Madrid, Francisco Sanz, 1672, s.p.

“9 En La prueba de la hermosura lo llama "Apeles del cielo". Cito por Armas, "Pintura y poesia ...», op. cit., pág. 725.
} 
La comparación retórica entre un pintor y el de Alejandro fue una práctica muy querida por la literatura de la época. Llamar el "Apeles español» a algún artista se hizo muy frecuente para ponderar sus cualidades; y también fue habitual utilizar su nombre para alabar no a un artista sino a un cuadro.

Su conversión en arquetipo queda ampliamente demostrada en los ejemplos anteriores, que se pueden ampliar indefinidamente. Incluso hay testimonios que sugieren que su nombre se propagó a través de la literatura popular, como indican unos versos que se incluyen en la comedia de Lope de Vega Al pasar el arroyo: «Lo bueno, hermano, ha de ser, / para el amigo que os ama, / para lo que bien queréis, / como aquella historia encarga / de Apeles y de Alejandro, / que hasta los niños la cantan" ${ }^{50}$. Hasta nuestros días han llegado alusiones folklóricas al pintor, como la que aparece en una canción de mayo recogida en Hontoba (Guadalajara).

La conversión de Apeles en arquetipo de pintor se explica porque su leyenda estaba plagada de episodios que resolvian los problemas artísticos de acuerdo con los deseos de buena parte de los escritores de la época. De entre ellos, los que más interesaban en la España del Siglo de Oro eran los que tenían que ver con su relación con Alejandro. En una época en la que los artistas luchaban por su reconocimiento social e intelectual, en la que la pintura se justificaba por su contribución a propagar la religión - la ideología política y en la que la sociedad tenía una estructura estamental que convertia al rey en el principal punto de referencia, es natural que aquellos interesados en la defensa de la pintura hicieran hincapié en la protección de los poderosos hacia este arte. Y aunque con frecuencia recurrieron a ejemplos modernos, la alusión más habitual fue a Apeles.

De su relación con Alejandro el episodio más repetido fue el de la cesión que el príncipe hizo al pintor de su favorita Campaspe, de la que se había enamorado éste mientras la retrataba. Sus ingredientes novelescos la convirtieron en la anécdota relacionada con un pintor antiguo más utilizada por la literatura del Siglo de Oro, y se empleó como ejemplo de amistad, como prueba del autocontrol de un príncipe como Alejandro y como testimonio de los honores a los que han sido acreedores los grandes artistas. También se utilizó con frecuencia el relato de la conversión de Apeles en retratista único de Alejandro, que quería de esa manera controlar su imagen pública. El tema proporcionaba una solución a un problema que se planteó en la Corte española durante las primeras décadas del

50 Comedias escogidas de Lope de Vega, t. II, Madrid, Atlas, 1950, pág. 403a. 
siglo XVII, como fue el de la proliferación de retratos reales cuya ínfima calidad atentaba contra el decoro que se suponía debía tener la imagen del monarca. No faltan tampoco alusiones a otros relatos antiguos relacionados con Apeles, como el de su contienda con Protógenes o el de la ejecución de una pintura con el tema de La Calumnia. Entre todos sirvieron para difundir la imagen de un pintor de grandes habilidades técnicas, que se guiaba de su inteligencia y su cultura para construir las historias de sus cuadros, que puso su arte al servicio del Estado y que mereció la estima de su príncipe, quien llegó a desprenderse de lo que más quería para recompensarle. Es decir, su historia se convirtió en una bandera a través de la cual se pudo reivindicar un determinado estatus social e intelectual para la pintura.

Aunque muchas de las alusiones a los pintores antiguos si se contemplan aisladas pueden justificarse como simples muletillas de los escritores para arropar su discurso literario, lo cierto es que fueron tan numerosas y se incluyen en contextos tan variados que no se puede menospreciar su importancia para la difusión de una imagen del artista. Si bien, desde un punto de vista doctrinal, fueron los tratados de retórica las fuentes sobre las que se construyeron las bases para la creación de la doctrina humanista de la pintura, la obra de Plinio y la variedad de anécdotas utilizadas por otros escritores sirvieron para dar un soporte trasladable a la experiencia cotidiana a esa doctrina. Apeles, Zeuxis o Timantes se convirtieron así en el horizonte mítico de la historia de la pintura, y ello se advierte muy bien en los tratados de arte.

Un ejemplo de la importancia de este tipo de referencias en la literatura del Siglo de Oro nos lo da la comparación de las biografías de Velázquez que publicaron Palomino en 1724 y Ceán en 1800. Ambas contienen una información semejante, pero cambia mucho, por el contrario, el tono, que en Ceán es contenido, claro y más bien aséptico, y en Palomino es retórico y admirativo. Estas diferencias se deben a los propósitos de las respectivas obras y al distinto concepto de historia que existía. Palomino escribe una historia apologética encaminada a demostrar la nobleza de la pintura mediante la exaltación de las glorias nacionales; y para ello recurre no sólo a un estilo hiperbólico, sino también a una narración en la que se intercalan anécdotas mitificadoras y referencias constantes a pintores de la Antigüedad, que era el horizonte ennoblecedor por excelencia. Así, son varias las ocasiones en las que compara a Velázquez con Apeles. Ceán, por el contrario, escribe su obra en un momento en el que la Academia de San Fernando era ya una institución firmemente asentada, cuya existencia y actividad eran la mejor prueba del estatus liberal del arte, y por lo tanto habían desaparecido muchos motivos de reivindicación. Es un momento 
también en la que existe una concepción distinta de la historia, que se concibe primordialmente como actividad basada en la veracidad y construida mediante instrumentos documentales, y que busca ante todo la reconstrucción e interpretación de unos hechos, y no sólo la legitimación de unos intereses. En ese contexto, sobraban las referencias a los pintores antiguos ${ }^{51}$.

La nómina de los pintores míticos en la España del Siglo de Oro no se acababa con los artistas griegos ya citados. En una sociedad ideológicamente teocéntrica, gran parte de cuyo arte estaba al servicio de la religión y se justificaba precisamente por su utilidad devocional, es muy natural que surgieran relatos en los que confluían el tema de la personalidad artística y el misterio religioso. Según un tópico extraordinariamente extendido, Dios actuó como gran pintor durante la Creación ${ }^{52}$; y no faltan importantes personajes sagrados de los que se asegura que habian tomado los pinceles, entre ellos el evangelista San Lucas ${ }^{53}$. La cantidad de referencias rastreables en la literatura de la época sobre estos asuntos es muy elevada, y conviven con otras historias en las que se recalca el auxilio divino hacia el arte y los artistas. Aunque en algunos casos sus difusores eran conscientes de su carácter legendario, en otros se transmitian como hechos históricos que entraban en la categoria de lo milagroso. Son incontables los relatos de este tipo, como el que incluye Lope de Vega en su Peregrino en su patria sobre un pintor a la vez devoto de la Virgen y enamorado de una mujer casada, que fue salvado de morir ejecutado por la intervención milagrosa de aquélla ${ }^{54}$; y cualquier madrileño sabía que Gaspar Becerra sólo pudo acabar la imagen de Nuestra Señora de la Soledad tras un sueño milagroso ${ }^{55}$.

\footnotetext{
Véase Javier Portus, “Tres miradas ilustradas a Velázquez: Mengs-Jovellanos-Ceán Bermúdez», en Jesusa VEGA (ed.), Goya y Velázquez, Zaragoza, Diputación General de Aragón, (en prensa).

${ }_{52}$ Véase, entre muchos otros, Ernst R. Curtius, Literatura europea y Edad Media latina, México, F.C.E., 1976.

${ }_{53}$ Sobre San Lucas véase José Hernandez Diaz, “El evangelista San Lucas, historiador, médico y pintor", Boletín de Bellas Artes, t. XII (1984), págs. 91-130.

${ }_{54}$ Lope de VEGA, El peregrino en su patria, ed. J.B. Avalle-Arce, Madrid, Castalia, 1973, págs. 154-157.

55 La historia de la imagen fue narrada en Antonio ARES, Discurso del ilustre origen y grandes excelencias de la misteriosa imagen de nuestra Señora de la Soledad del convento de la Victoria de Madrid, Madrid, 1640 (transcrito parcialmente en José SIMÓN Diaz, Fuentes para la historia de Madrid y su provincia, Madrid, Instituto de Estudios Madrileños, 1964).
} 
Con todo ello vemos que los dos puntos de referencia fundamentales del horizonte cultural de la Edad Moderna (la religión y la Antigüedad) eran una cantera de información sobre los artistas que se explotó para extraer de ella relatos que servían para construir una imagen generalmente ennoblecedora del pintor.

Pero no todas las referencias literarias ofrecian una visión tan nítida, y a veces encontramos acercamientos paródicos al arte y los artistas, como los que nos ofrecen los cuentecillos, que eran relatos breves generalmente insertos en contextos más amplios y que en ocasiones tenian un origen folklórico, aunque abundan aquellos que procedían de la literatura antigua. Las leyes del género obligaban a utilizar la parodia y la paradoja, y en ese sentido es natural que los temas artísticos estén tratados en clave de humor. Lo realmente singular de ellos no es ese tono imprescindible, sino el hecho de que comparativamente sean muchos los relatos de este tipo que tienen a los pintores como protagonistas, lo que se debe a las posibilidades paródicas que ofrece la relación entre realidad e imagen o la convivencia entre el artista y su cliente. Ese hecho es también índice de la importancia que tenía la figura del pintor en el contexto de los tipos profesionales de la España de la época.

Aunque se usa la parodia, hay que decir que la imagen colectiva del pintor no sale malparada. Hay que pensar a este respecto que dos de los literatos más amigos de utilizar este tipo de anécdotas en sus obras, como fueron Lope de Vega y Calderón, se cuentan entre los escritores más firmemente convencidos de la dignidad del pintor y de su arte, y entre los que hicieron esfuerzos concretos para inmiscuirse en favor de los intereses profesionales de sus amigos los artistas.

En realidad, la visión que se ofrece en los cuentecillos sobre el artista es bastante positiva, porque a través de la burla de los malos pintores se está afirmando la dificultad de ese arte y la posibilidad de que haya alguien que lo practique mal; y a través de los relatos sobre la relación con los clientes se prueba hasta qué punto el juicio y el ingenio son factores importantes en la creación pictórica. El tema es tanto más importante cuanto que se trataba de piezas que se insertaban en contextos literarios muy diferentes y variados, y cuyo conocimiento probablemente llegaba a gran parte de la población. 
Unas cuantas tenian como protagonistas a malos pintores que eran incapaces de solventar con soltura los problemas de la representación. El más conocido es el de aquel que tuvo que escribir debajo de la imagen qué es lo que había querido representar, pues de otro modo era imposible saberlo. Está recogido en numerosas obras y contempló algunas variantes. Entre los escritores que lo utilizaron figura Cervantes, que dio nombre, Orbaneja, a ese mal pintor, y que se sirvió de la anécdota para, por vía de comparación, hacer una crítica de carácter literario. Es una narración que ha trascendido al folklore popular, pues se enfrenta a un tema esencial de la actividad artística, como es el del parecido o el de las relaciones entre objeto real y objeto representado. Sin embargo, su origen es culto, y puede rastrearse en algunos escritores grecolatinos, como Eliano ${ }^{56}$.

También protagonizado por un pintamonas y procedente de un relato clásico (en este caso de Plutarco) es el cuento sobre un artista que pintó mal un gallo y, en palabras del predicador Cabrera, "cuando sacó la pintura a vistas, puso un muchacho que con una larga caña afease de la plaza todos los gallos vivos que andaban por ella, porque su presencia no descubriese la impropiedad de su tabla» ${ }^{57}$. Un tercer cuentecillo de este tipo lo protagoniza un artista que, cuando un amigo le comunica que va a blanquear su casa, le propone hacerle una pintura en la pared, a lo que éste responde que sería mejor que primero pintase y después él blanquearía. Lo más significativo de estas anécdotas es que siempre se coloca el adjetivo "malo" antes que el nombre "pintor», lo que sirve para transmitir la idea de que la pintura es una actividad difícil, es decir, es un arte que no puede cultivar bien cualquiera, que requiere estudio y que está sujeto al juicio de los demás. De todo ello se hace eco otro cuentecillo que procede del refrán latino "Mejor es ser médico que pintor", y que Melchor de Santa Cruz transmitió así en su Floresta española: "Un mal pintor que nunca vendía obra que hacia, fuese a otro lugar y hízose médico. Pasando por alli uno que le conocia, le preguntó que por qué era la causa que andaba en hábito de médico pues era pintor. Respondió: Quise tomar oficio que las faltas que hiciese cobije la tierra" ${ }^{58}$.

Un tema habitual en los cuentecillos fue el de la relación entre el pintor y sus clientes, que frecuentemente toma la forma de respuesta ingeniosa

56 Del tema he tratado en "Un cuentecillo del Siglo de Oro sobre la mala pintura: Orbaneja", Boletín de la Institución Libre de Enseñanza, n. ${ }^{\circ} 5$ (1988), págs. 46-55 (También incluido en Miguel MORÁn y Javier PORTús, El arte de mirar. La pintura y su público en la España de Velázquez, Madrid, Istmo, 1997).

57 Cito por HeRRERO, Contribución ..., op. cit., pág. 221.

s8 Cito por Sanchez Cantón, Fuentes literarias ..., op. cit., t. v, pág. 354. 
de aquél para justificar sus estrategias de representación. En todos ellos se sigue jugando con la tensión entre imagen y realidad que ya vimos era tema central en otros relatos. Uno de los más conocidos es el que alude a un artista que tiene que resolver el complicado problema de la representación de Santa Úrsula y las once mil vírgenes, para lo que recurre a pintar a la santa con una pocas de sus compañeras y sugerir las cabezas de una multitud detrás. De entre todas las versiones interesa especialmente la que recogió «El Encogido" en su Discurso a la devoción de San Francisco, que nos ofrece una visión positiva del artista cuando explica que éste "viendo al imposible que lo obligaban, aprovechóse de su prudencia y ciencia y pintó una puerta de una casa, y en ella una virgen sola. Volviendo su dueño por el cuadro y viendo aquella pintura pidió por las demás vírgenes, a que respondió el pintor que en saliendo aquella saldrian las demás» ${ }^{59}$.

Una prudencia y ciencia similares utilizó el pintor que cuando tuvo que pintar el Juicio de Paris y llegó el momento de representar a la diosa Venus, optó por ponerla de espaldas ante la imposibilidad de transmitir su perfecta belleza. Es una historia que narran, entre otros, Gabriel Bocángel o Lupercio Leonardo Argensola ${ }^{60}$ y que, como el lector ya habrá notado, se relaciona directamente con la famosa historia del velo de Timantes. En ocasiones, sin embargo, el ingenio no le servía al pintor para resolver los problemas de la representación sino para justificar errores iconográficos imperdonables, como el que cometió un artista que pintó trece apóstoles en la Última cena, de lo que se excusó diciendo que el decimotercer invitado "no hará sino cenar y marcharse" ${ }^{61}$.

Los cuentecillos a veces se sirven de la paradoja para abordar cuestiones esenciales de la creación artística. La tensión subyacente entre arte y vida, entre creación artística y perpetuación biológica se expresa en un relato que toma numerosas variantes y que fue muy difundido. Trata sobre un pintor que aunque era capaz de producir obras muy hermosas, sólo sabía engendrar hijos feos. $Y$ el tema de las relaciones entre materia y forma, un problema nuclear de la conciencia artística, dio lugar a conocidos cuentecillos sobre "San Ciruelo", es decir, sobre campesinos que se

\footnotetext{
59 Biblioteca Nacional de Madrid, Mss. 3672, fol. $28 \mathrm{r}$.

60 Gabriel BocAngel, Declamaciones castellanas, En Obras de Gabriel Bocángel, ed. R. Benítez, Madrid, CSIC, t.II, 1946, pág. 26. Lupercio LEONARdo ARgENSOLA, "Licinio a Flora", en Biblioteca Nacional de Madrid, Mss. 2883, págs. 65-66.

6. Aparece, entre otros muchos ejemplos, en la comedia de Lope Amar sin saber a quien (Comedias escogidas de Lope de Vega, Madrid, Atlas, 1950, t. II, pág. 457). M. BuChanaN, "Short Stories and Anecdotes in Spanish Plays", Modern Language Review, t. V (1910), pág. 83, cree que tiene antecedentes en relatos italianos.
} 
asombran al ver convertido en santo aquello que ellos habían conocido como árbol. El tema encuentra numerosas variantes en la literatura culta, alude a la estupefacción que acompaña siempre al misterio de la reproducción de la realidad y se recoge también en manifestaciones expresivas de carácter folklórico ${ }^{62}$.

Si en los casos anteriores es posible identificar las razones que hacian risible un relato, existen varios cuentos en los que no resulta fácil esta operación, y con su hermetismo nos revelan que existen parcelas de la relación entre el hombre de la Edad Moderna y la creación artística que actualmente se nos escapan. A este respecto, hay que recordar que los cuentecillos apelaban de forma directa y fácil a la inteligencia de sus múltiples receptores, y en ellos no existía el propósito de reservar parte de su significado a unos pocos iniciados. Estos relatos cuyo sentido paródico actualmente se nos escapa muestran al pintor como un ser tozudo que trata de imponer sus absurdas preferencias a sus clientes. Sebastián Mey, en su Fabulario nos presenta a uno empeñado en pintar imágenes de San Antón, aunque lo que le encargan es un San Cristóbal ${ }^{63}$; y Lope de Vega, en su elogio a Manuel Faria por su traducción de las Luisiadas de Camoens, alude a un artista que en todas sus obras introducía un ciprés, viniera o no a cuento ${ }^{64}$. Habría que preguntarse si esa tozudez no se utiliza como reflejo de una imagen del pintor como un ser con personalidad propia más allá de las pretensiones de su propia clientela.

Aunque los cuentecillos frecuentemente tuvieron un origen culto, trascendieron al folklore y acabaron siendo en muchos casos del dominio público. Su importancia para la transmisión de una imagen del pintor al grueso de la sociedad es compartida por otro género literario con una dimensión genuinamente pública: el teatro. Se trata de una de las formas de expresión masivas más importantes de la España del Siglo de Oro, y sirvió como privilegiado medio de transmisión de la ideología del poder. En esa época fue muy frecuente la inclusión en las obras dramáticas no sólo

62 He tratado del tema en «De madero a imagen: San Ciruelo», Cuadernos de Arte e lconografia, VI/12 (1993), págs. 160-167. También incluido en Morán y Portús, El arte de mirar..., op. cit.

63 Ed. C. Bravo Villasante, Madrid, F.U.E., 1975, págs. 36-37. La obra data de 1613.

${ }^{64}$ Lope de Vega, Colección de obras sueltas, asi en prosa como en verso, de Lope de Vega, Madrid, Sancha, 1776-1779, t. XVII, pág. 350. 
de alusiones a artistas y obras de arte, sino también de personajes que trabajaban como pintores. Al tema dedicamos hace unos años un artículo en esta misma revista ${ }^{65}$, por lo que aquí nos vamos a limitar a resumir las características principales de la imagen que se transmitió de los pintores a través de los escenarios.

Los pintores que aparecen en el teatro español de la época se adecuan perfectamente a la imagen de artistas nobles, intelectuales y útiles para con su sociedad que transmiten los tratados artísticos. Las únicas excepciones son los que protagonizan entremeses y obras semejantes, en las que, como en los cuentecillos, se jugaba con las posibilidades paródicas y paradójicas del arte y sus creadores. El propio Dios, en su faceta de pintor de la Creación, protagoniza el auto sacramental El pintor de su deshonra, de Calderón; San Lucas reflexiona sobre la elevada utilidad religiosa de su actividad artística en El médico pintor: San Lucas, de Fernando de Zárate; el gran honor que hizo Alejandro a Apeles cediéndole a su favorita Campaspe, y las excelencias artísticas de este pintor, son la parte fundamental de Las grandezas de Alejandro de Lope de Vega, Darlo todo y no dar nada, de Calderón y La mayor hazaña de Alejandro Magno, de autor desconocido; otro artista clásico (aunque inventado), Elpenor, expresa su preparación científica mientras realiza un retrato de un príncipe; Tiziano es uno de los personajes de La Santa Liga, una comedia de Lope en la que se insiste en lo mucho que honró el senado veneciano al pintor; El Greco es una referencia latente en Gridonia o Cielo de amor vengado de Hortensio Félix Paravicino; el protagonista de la comedia El pintor de su deshonra de Calderón es un noble barcelonés aficionado a pintar que convierte esta afición en un instrumento para vengar sus celos; y Los Ponces de Barcelona, de Lope de Vega, está protagonizada por la hija de un pintor y contiene una de las defensas más hermosas, dignas y exaltadas que se han hecho nunca del arte de la pintura. Otras obras, como Ya anda la de Mazagatos, La ilustre fregona, También la afrenta es veneno o Peribáñez y el comendador de Ocaña también incluyen entre sus personajes a pintores, que en muchos casos proyectan una imagen noble de su actividad.

Dado el carácter masivo del público de estas comedias y la influencia social de sus autores, no debemos considerarlas tanto reflejo de una imagen ya extendida de los pintores cuanto instrumentos para difundir entre la sociedad unas nociones determinadas sobre el arte y los artistas. En la

65 "Entre el divino artista y el retratista alcahuete: El pintor en la escena barroca española", Espacio, Tiempo y Forma, Serie VII, t. V (1992), págs. 185-210. 
época en la que escribió Lope de Vega, los pintores todavía luchaban por el reconocimiento del carácter noble y liberal de su actividad en una sociedad que en muchos casos era muy poco receptiva a sus pretensiones. En sus reivindicaciones encontraron apoyo en algunos literatos que procedian de su mismo medio social, que eran aficionados al arte y con los que les unian relaciones de familia y amistad. Y Lope contribuyó decisivamente en esta tarea no sólo escribiendo algún memorial en defensa explícita de la pintura, sino prodigando las referencias al arte y los artistas en sus obras y, sobre todo, mostrando al masivo público de sus comedias ejemplos de pintores que merecian la confianza y la estima de sus príncipes. De la situación social de los pintores y de la utilización del teatro como instrumento reivindicativo es un magnífico ejemplo la ya citada Los Ponces de Barcelona, protagonizada por la hija de un pintor que aspira a casarse con el hijo de un noble. Cuando la pareja expone a éste sus intenciones, entra en cólera indignado por la baja condición social de la novia. Con ello, Lope no hacía sino exponer el punto de vista de una parte muy importante de la audiencia. Pero la contestación de la mujer es un auténtico alegato en favor de la dignidad del arte, y en ella se rebaten todos los prejuicios del noble. Al final, tras múltiples peripecias la pareja consigue sus propósitos y Lope, que no era nada amigo de incluir matrimonios desiguales en sus comedias, demuestra que la nobleza que puede proporcionar el cultivo de un arte como la pintura es comparable a la que procede de la sangre.

El ejemplo del teatro de Lope de Vega nos enseña que en la España del Siglo de Oro la literatura se puso en ocasiones al servicio de los pintores con objeto de difundir entre toda la sociedad una imagen acorde con las aspiraciones profesionales de éstos.

En la rica poesía del Siglo de Oro muy frecuentemente aparecen involucrados nombres de artistas modernos, ya sea porque son ellos mismos los protagonistas de los poemas o porque éstos están dedicados a obras suyas. Una rápida enumeración de algunos de los literatos, pintores y escultores relacionados con estas composiciones puede ayudarnos a comprender hasta qué punto estamos ante un fenómeno que permite hablar de una «imagen poética» del artista. Entre los escritores que compusieron versos sobre el tema figuran Gabriel Bocángel, Francisco de Quevedo, Anastasio Pantaleón de Ribera, Joaquín Benagassi, Lope de Vega, o Bances Candamo, y entre los pintores y escultores que fueron objeto de 
elogios poéticos se pueden citar, entre otros muchos, a El Greco, Navarrete el Mudo, Juan Bautista Maíno, Felipe Liaño, Diego Velázquez, Vicente Carducho, Juan Fernández Labrador, Juan Carreño de Miranda, Alonso Cano, Pedro de Mena, Juan Bernabé Palomino, etc. Gran parte de los principales literatos de la época dedicaron alguna composición poética a artistas y a obras de arte contemporáneos, y muchos de los mejores pintores fueron objeto de elogios poéticos. El tema es interesante y aunque en la mayor parte los argumentos se limitan a tópicos extendidos sobre la creación artística y la personalidad del pintor, lo cierto es que el estudio detenido de estas composiciones puede ayudar no sólo a perfilar la imagen literaria y, por extensión, social del artista en el Siglo de Oro, sino también a identificar las distintas relaciones de familia, amistad, admiración o profesión que unían frecuentemente a ciertos pintores con algunos literatos.

Estos poemas siempre revelan una relación que, como hemos dicho, podía adquirir formas muy variables. Las composiciones de Lope deVega dedicadas a Liaño son testigo de la estrecha amistad que les unia; el romance de Bances Candamo dedicado a la Magdalena de Pedro de Mena en parte se justifica por la existencia de vínculos familiares entre ellos; el soneto de Bocángel en alabanza de Martínez Montañés por su retrato esculpido de Felipe IV testimonia su común dependencia laboral respecto a Felipe IV; en los poemas que se escribieron por el retrato ecuestre de Felipe IV de Rubens convive la admiración por el autor con la adulación hacia el soberano, etc. Lo más destacable es que son relativamente abundantes las obras de este tipo y que, excepto en contados casos como el poema en el que Quevedo se burla de un cuadro mal pintado por Cajés, se transmite una imagen francamente positiva del pintor como un ser socialmente equiparable al escritor y que merece la estima y la admiración de este por su maestría artística o por la utilidad social, religiosa o política de sus obras.

Otro aspecto significativo de la imagen literaria del pintor durante el Siglo de Oro es la existencia de una especie de catálogo de artistas más o menos modernos estimables, por lo general ya muertos y que marcaban una línea de continuidad respecto a los pintores griegos citados anteriormente. Es decir, desde la literatura se era plenamente consciente de que la pintura tenía una historia y era posible hablar de los artistas en relación a una tradición reseñable. A cada uno de esos pintores modernos que se convirtieron en lugares comunes le caracterizaba una especialidad temática o un rasgo estilístico. Miguel Ángel era el ingenio, la soberbia y el impudor, El Bosco las bizarrías, la imaginación y los caprichos, Tiziano la mitología y la maestría narrativa, Navarrete se convirtió en el representante español por excelencia de la lista de artistas mitificados, etc. 
Curiosamente, se produjo en algún caso el fenómeno de mitificación en vida, como ocurrió con Rubens, que deslumbró a Lope de Vega, quien enseguida advirtió que se encontraba ante la réplica estrictamente contemporánea de Tiziano. De hecho, a partir de su llegada a España, el flamenco sustituyó al veneciano en la pluma de Lope como ejemplo de artista genial.

A través de este rapidísimo repaso a la imagen literaria del pintor en la España del Siglo de Oro creo que hemos podido comprobar lo mucho que este tipo de artista se cita en todo tipo de expresión escrita, la gran variedad de contextos en los que aparece y la amplia casuística que es posible formar. Pero el estudio de las alusiones literarias no es sólo válido para reconstruir esa imagen, sino que permite también acercarse al conocimiento de los mecanismos a través de los cuales el pintor y la pintura afirmaron cada vez con mayor fuerza su presencia en una sociedad variada y compleja. De hecho, la imagen literaria del artista en muchos casos no fue tanto un reflejo de su imagen social, cuanto un arma que utilizaron algunos escritores cercanos a los pintores para concienciar a la sociedad sobre el respeto y el honor debidos a las buenas pinturas y a sus creadores. 
